\title{
Microtubules and Vimentin Fiber Stability during Parabolic Flights
}

\author{
Simon L. Wuest ${ }^{1}$ (iD - Jaro Arnold ${ }^{2} \cdot$ Sarah Gander $^{3} \cdot$ Christoph Zumbühl $^{3} \cdot$ Christian Jost $^{3} \cdot$ Christina Giger-Lange $^{1}$. \\ Geraldine Cerretti ${ }^{1}$ (D) Martina Caliò ${ }^{1} \cdot$ Karin Rattenbacher-Kiser ${ }^{1} \cdot$ Cindy Follonier $^{1} \cdot$ Othmar Schälli $^{3}$. \\ Gerhard S. Székely ${ }^{2}$ (I) $\cdot$ Marcel Egli ${ }^{1}$ (I) $\cdot$ Fabian Ille $^{1}$ (i)
}

Received: 20 March 2020 / Accepted: 8 July 2020 / Published online: 19 July 2020

(C) The Author(s) 2020

\begin{abstract}
Adequate mechanical stimulation is essential for cellular health and tissue maintenance, including articular cartilage, which lines the articulating bones in joints. Chondrocytes, which are the sole cells found in articular cartilage, are responsible for matrix synthesis, maintenance and degradation. It is generally believed that chondrocytes require mechanical stimuli through daily physical activity for adequate cartilage homeostasis. However, to date, the molecular mechanisms of cellular force sensing (mechanotransduction) are not fully understood. Among other mechanisms, the cytoskeleton is thought to play a key role. Despite that gravity is a very small force at the cellular level, cytoskeletal adaptations have been observed under altered gravity conditions of a parabolic flight in multiple cell types. In this study, we developed a novel hardware which allowed to chemically fix primary bovine chondrocytes at 7 time points over the course of a 31-parabola flight. The samples were subsequently stained for the microtubules and vimentin network and microscopic images were acquired. The images showed a large heterogeneity among the cells in morphology as well as in the structure of both networks. In all, no changes or adaptions in cytoskeleton structure could be detected over the course of the parabolic flight.
\end{abstract}

Keywords Articular chondrocytes · Cytoskeleton adaptation · Tubulin · Vimentin · Gravity · Parabolic Flight

\section{Introduction}

Adequate mechanical stimulation is essential for cellular health and tissue maintenance, such as in articular

This article belongs to the Topical Collection on The Effect of Gravity on Physical and Biological Phenomena

Guest Editor: Valentina Shevtsova

Electronic supplementary material The online version of this article (https://doi.org/10.1007/s12217-020-09818-8) contains supplementary material, which is available to authorized users.

Fabian Ille

fabian.ille@hslu.ch

1 Institute of Medical Engineering, Space Biology Group, Lucerne University of Applied Sciences and Arts, School of Engineering and Architecture, Hergiswil, Switzerland

2 Institute of Mechanical Engineering and Energy Technology, Lucerne University of Applied Sciences and Arts, School of Engineering and Architecture, Horw, Switzerland

3 Institute of Electrical Engineering, Lucerne University of Applied Sciences and Arts, School of Engineering and Architecture, Horw, Switzerland cartilage, which lines the articulating bones in joints. Articular cartilage absorbs shocks, reduces friction and wear and allows almost effortless movement. While an active lifestyle is beneficial to maintain healthy cartilage, prolonged mechanical unloading or overloading can lead to a pathological breakdown of articular cartilage and a subsequent development of osteoarthritis (reviewed in (Bennell and Hinman 2011; Roos and Arden 2016)). Bedrest studies, animal models and clinical studies on astronauts showed that mechanical unloading eventually leads to irreversible cartilage degradation (reviewed in (Johnston et al. 2010; Fitzgerald 2017; Ramachandran et al. 2018)).

Chondrocytes are the sole cells found in articular cartilage and are responsible for matrix synthesis, maintenance, and degradation (reviewed in (Buckwalter et al. 1994; Haqqi et al. 2000; Ulrich-Vinther et al. 2003; Akkiraju and Nohe 2015)). Since chondrocytes are exposed to mechanical loading during daily physical activity, it is generally believed that chondrocytes require mechanical stimuli for adequate cartilage homeostasis (reviewed in (Mobasheri et al. 2002; Grad et al. 2011; Anderson and Johnstone 2017)). However, to date, the molecular 
mechanisms on how cells incorporate a mechanical force into a cellular response (mechanotransduction) are not fully understood (reviewed in (Wang and Thampatty 2006; Loon 2007; Eyckmans et al. 2011; Wang et al. 2014; Wang 2017)). Among other mechanisms, the cytoskeleton is thought to play a key role in mechanotransduction (reviewed in (Wang 2017; Eyckmans et al. 2011; Ingber 2003b; Wang et al. 2009; Vorselen et al. 2014; Ohashi et al. 2017)). The cytoskeleton is involved in many cellular functions including proliferation, migration and differentiation and largely determines the mechanical properties of a cell (reviewed in (Ingber 2003a; Janmey and McCulloch 2007; Fletcher and Mullins 2010; Rajagopal et al. 2018)). Even though gravity is a tiny force at the cellular level, cytoskeletal rearrangements or adaptations have been observed under altered gravity conditions of a parabolic flight in multiple cell types (Rosner et al. 2006; Yang et al. 2010; Ulbrich et al. 2011; Grosse et al. 2012; Aleshcheva et al. 2015; Corydon et al. 2016). Studies on articular chondrocytes showed a disruption of the tubulin network and holes in the vimentin and cytokeratin network after 31 parabolas, but not after one parabola (Aleshcheva et al. 2015). This data suggests a time-dependent reaction of the tubulin and vimentin cytoskeleton to parabolic flight conditions.

In this study, we address the question to what extent recurring parabolas affect the tubulin and vimentin cytoskeleton in primary chondrocytes. Therefore, we developed a novel hardware to fix adherent cells chemically, at predefined time points during a parabolic flight. Using this hardware, bovine articular chondrocytes were fixed at 7 time points over the course of a 31-parabola flight, revealing no significant changes in their tubulin and vimentin cytoskeleton.

\section{Materials and Methods}

\section{Parabolic Flight}

The experiment was flown in an Airbus A310 operated by Novespace (Bordeaux, France) (Pletser et al. 2016) during the 71st European Space Agency (ESA) parabolic flight campaign. The experiment was performed on a single flight day, during which 31 consecutive parabolas were flown. Each parabolic maneuver consisted of three phases: a hypergravity period, followed by a microgravity period and concluded by a hypergravity period (Pletser and Kumei 2015; Karmali and Shelhamer 2008). Each phase was approximately $20 \mathrm{~s}$ long. During hypergravity phases, an acceleration between 1.8 and $2 \mathrm{~g}$ was acting on the cells. In the microgravity phase, the aircraft was flown along a parabolic trajectory that resulted in a free-fall, which was perceived as microgravity.

\section{Hardware}

\section{Fixation Units}

For this study, we developed a novel hardware to chemically fix adherent cells during the parabolic flight. The core element of the hardware was an assembly of a culture chamber, syringes and valves which allowed cultivation and rapid fixation of the cells (Fig. 1). The components of this assembly could be connected under a flow-bench in sterile condition. Subsequently, up to three of these assemblies could be mounted in a custom-made fixation unit (Figs. 1 and 2).
Fig. 1 In the fixation unit, assemblies of a culture chamber ( $\mu$-slides), syringes and valves, which allow cultivation and rapid fixation of the cells, were mounted. The fixative (FA) was stored in a $3 \mathrm{ml}$-syringe and injected by a linear actuator. During fixation, waste medium was collected in an empty syringe. Backcheck valves avoided undesired diffusion of fixative and prevented possible contamination. A 3-way valve was used to remove air bubbles and exchange culture medium. The components were connected by flexible silicone tubes

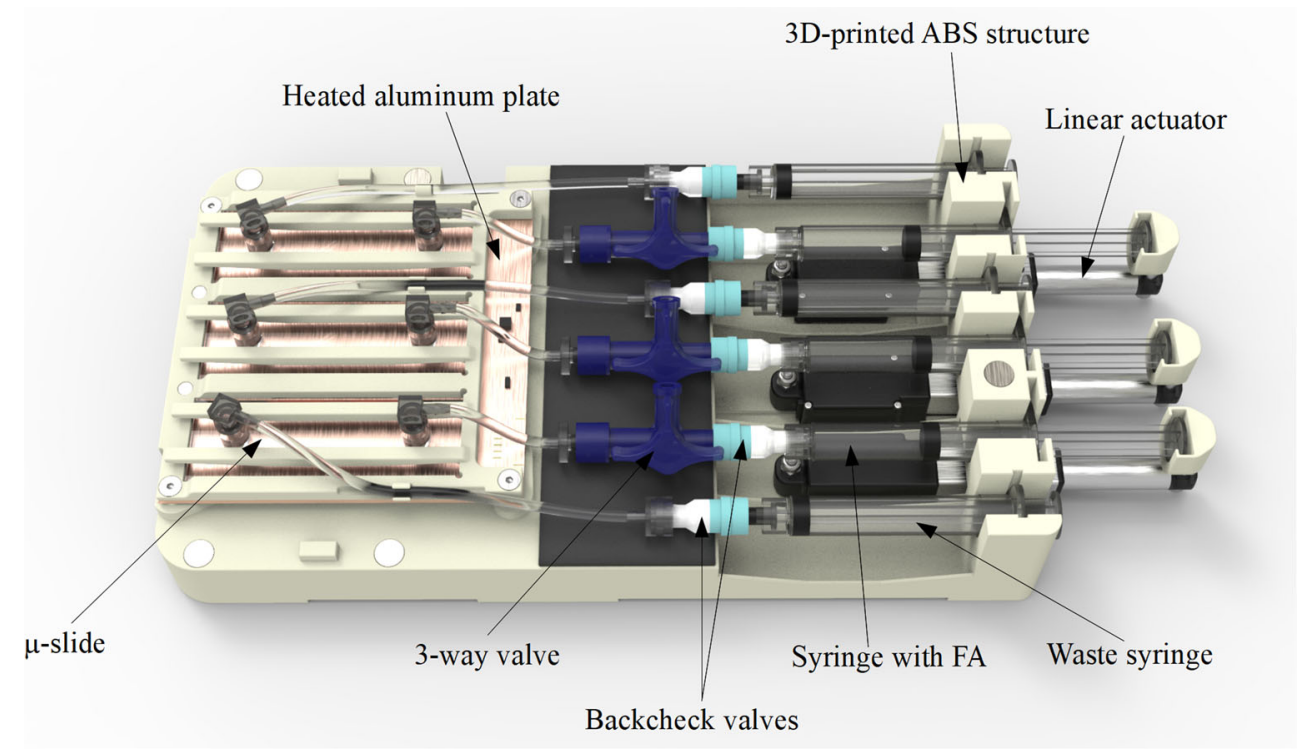


Fig. 2 The fluid exchange assemblies were mounted into the fixation unit without disconnecting any components and were secured with snap-on structures. The $\mu$-slides (holding the samples) were placed on a temperature stabilized aluminum plate. The unit was controlled by a microcontroller placed below the samples

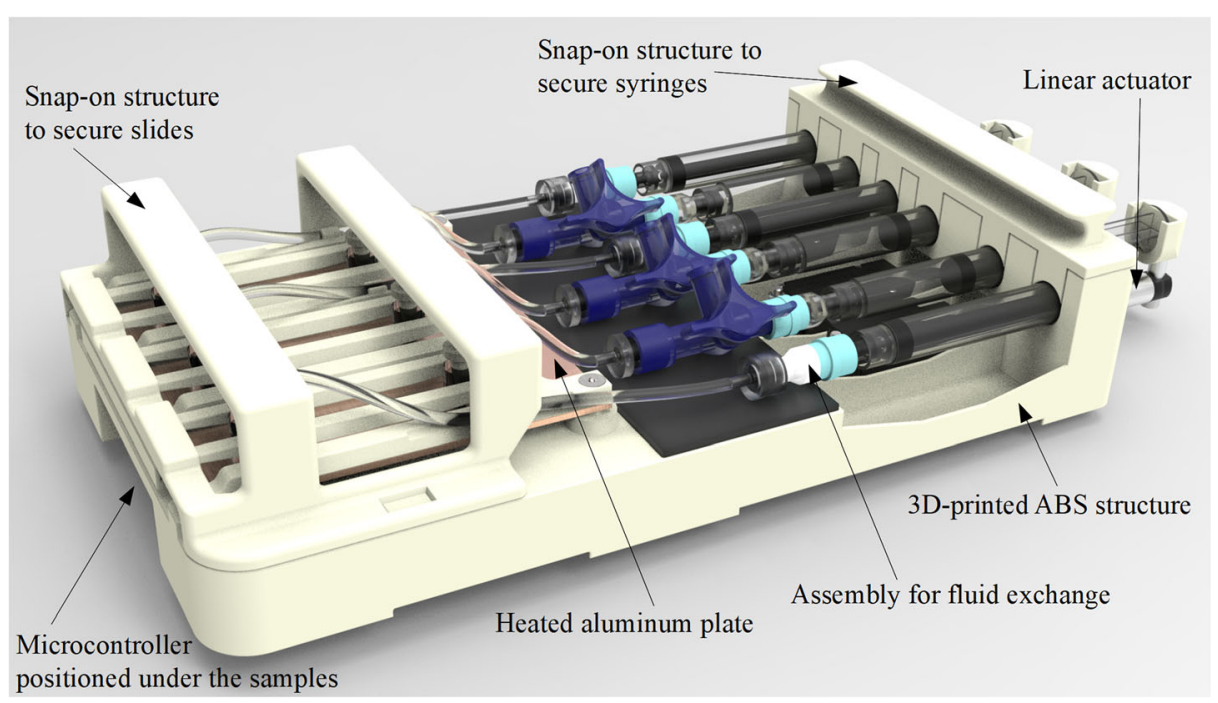

Commercial $\mu$-slides (ibidi, Gräfelfing, Germany) were selected as a culture chamber for the chondrocytes (coated with the manufacturers "ibidiTreat"). These slides feature a perfusion channel ( $0.8 \mathrm{~mm}$ high), allowing rapid medium exchange for fixation. The slides were also used for subsequent immunohistochemical staining and microscopy. The cells were fixed with $4 \%$ formaldehyde (FA), which was stored in a 3 ml-syringe (B. Braun, Sempach, Switzerland). During fixation, waste medium was collected in an empty $3 \mathrm{ml}$-syringe. Two backcheck valves (B. Braun, Sempach, Switzerland) attached to both syringes avoided undesired fixative diffusion and prevented possible contamination. In addition, a 3-way valve (B. Braun, Sempach, Switzerland) was used to remove air bubbles and exchange culture medium before the flight. The slides were connected by flexible silicone tubes to the syringes and valves.

The fixation unit structure (Figs. 1 and 2) was mostly manufactured from 3D-printed acrylonitrile butadiene styrene (ABS). The unit was designed such that the complete fluid exchange assemblies could be mounted without disconnecting any components to avoid contaminations. Fixative injection was driven by a linear actuator (Actuonix, Victoria, Canada), which replaced the cell culture medium by FA within two seconds. The $\mu$-slides, containing the cells, were placed on an aluminum plate, which was temperature-stabilized at $37^{\circ} \mathrm{C}$ by a heating foil (thermo Technologies, Rohrbach, Germany). Heating power was regulated by a microcontroller using two temperature sensors as a feedback. The whole fixation unit was controlled by a microcontroller (tinyK22 designed by the Lucerne School of Engineering and Architecture, Horw, Switzerland) located under the heated plate on a custom-made printed circuit board (PCB). This PCB interfaced to all peripheral devices and sensors. Besides controlling the temperature, the microcontroller also controlled the linear actuator and logged various housekeeping data including acceleration, temperature, air pressure, supply voltage and power consumption. In addition, the microcontroller provided a serial communication interface to an external board computer (laptop). Finally, for safety reasons, the fixation units were placed in a tight aluminum container to avoid environment contamination by media leakage (Fig. 3).

\section{Rack}

After the fixation units were prepared in the laboratory, they were mounted into the flight rack (Fig. 4). (The flight rack could accommodate up to 12 fixation units. Thus, up to 36 samples could be flown in one flight.) The rack was built according to the requirements of Novespace (Bordeaux, France) and was screwed to the aircraft floor. The rack was built from aluminum profiles (Bosch Rexroth, Lohr am Main, Germany) and aluminum plates forming a closed compartment for the fixation units. The units were packed in custom-made inserts of polyurethane foam (Vibraplast,

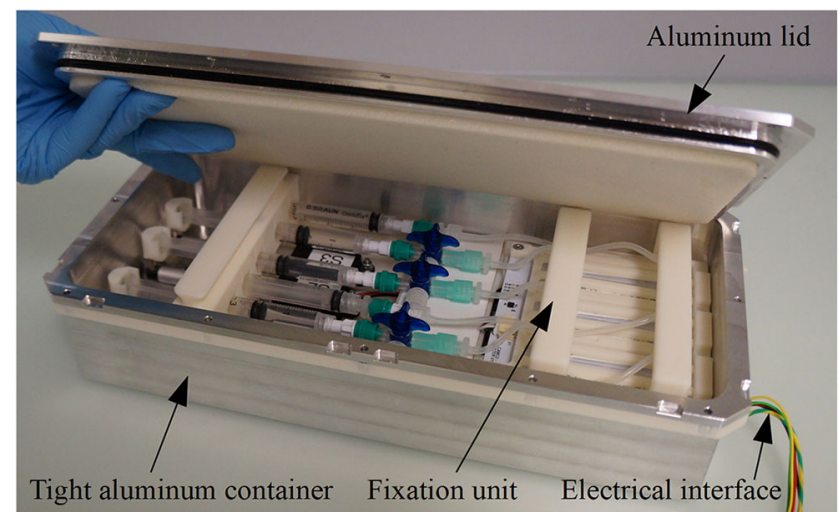

Fig. 3 The fixation units were placed in a tight aluminum container to avoid undesired loss of media 
Fig. 4 Up to 12 fixation units could be mounted into the flight rack, which was attached to the aircraft's floor (left). The units were packed in custom-made inserts of polyurethane foam to reduce mechanical vibration and ensure thermal insulation (right). Supportive devices as well as a laptop, controlling all fixation units and recording acceleration, were mounted on the rack as well

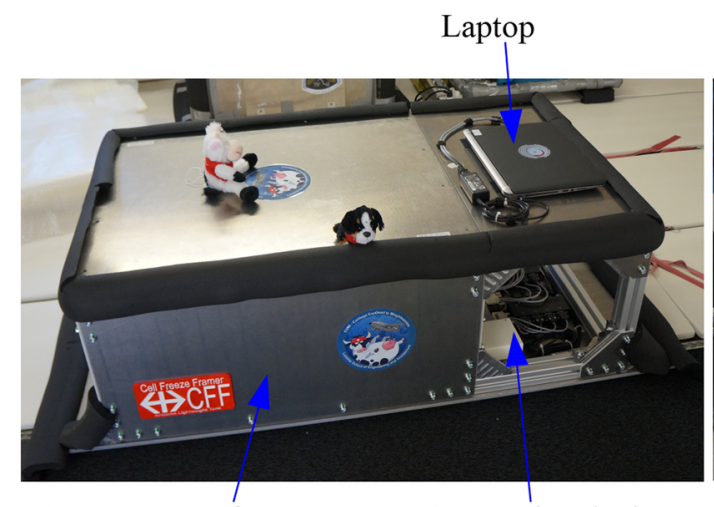

Compartment for fixation units

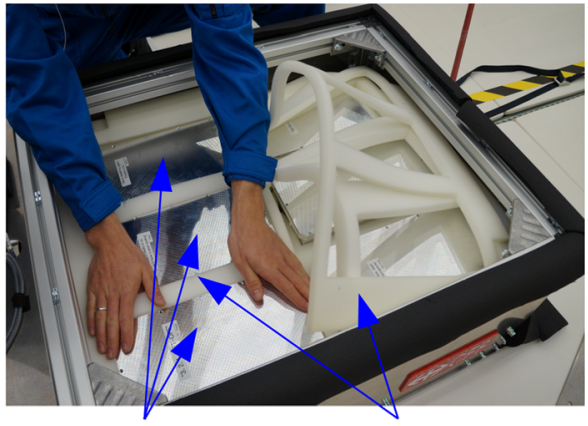

Fixation units
Polyurethane foam
Aadorf, Switzerland) to reduce mechanical vibration and ensured thermal insulation (Fig. 4). In addition, supportive devices such as a power supply, fuses and converters were mounted on the rack. Finally, a laptop running a custommade software was used to control all fixation units and record the experienced acceleration during the flight.

\section{Bovine Articular Chondrocytes and Cell Culture}

The isolation of primary bovine articular chondrocytes was carried out as previously described (Wuest et al. 2018), using distal interphalangeal joints (DIPs) of cattle obtained from a local butcher (food chain). Joints from cattle slaughtered on the same day were opened under aseptic conditions and the articular cartilage was removed with a surgical blade. The obtained pieces of cartilage were minced manually and the chondrocytes were subsequently isolated from the extracellular matrix by enzymatic digestion. First, the cells were incubated in $0.1 \%$ Pronase (Roche, Basel, Switzerland) in phosphate buffered saline (PBS, pH 7.4, Gibco brand of Thermo Fisher Scientific, Basel, Switzerland) for two hours at $37{ }^{\circ} \mathrm{C}$ with gentle rocking and then resuspended in Collagenase II (Worthington, Lakewood, NJ, USA) with an activity level of $600 \mathrm{U} / \mathrm{ml}$ and incubated overnight again at $37^{\circ} \mathrm{C}$ on the shaker. Subsequently, the cells were separated from remaining tissue by a cell strainer and washed with PBS. The isolated cells were finally resuspended in freezing medium (DMEM with low glucose, $20 \%$ FBS, $1 \%$ Penicillin-Streptomycin and $10 \%$ DMSO) and immediately frozen at $-80{ }^{\circ} \mathrm{C}$ until further processing.

Since chondrocytes are known to lose their phenotype in standard 2D cell culture (Wuest et al. 2018; Marlovits et al. 2004; Schulze-Tanzil 2009; Tekari et al. 2014; Barlič et al. 2008; Diaz-Romero et al. 2005; Diaz-Romero et al. 2008; Kang et al. 2007; Lin et al. 2008; Charlier et al. 2019), the cells were not expanded after isolation. Three days before the flight, the (non-passaged) cells were seeded in commercial T25 flasks. Cell culture medium contained low glucose (1 g/
1) DMEM, buffered with $25 \mathrm{mM}$ HEPES (Gibco brand of Thermo Fisher Scientific, Basel, Switzerland), and was supplemented with $10 \%$ fetal calf serum (FCS; Gibco brand of Thermo Fisher Scientific, Basel, Switzerland) and 1\% Penicillin Streptomycin (Gibco brand of Thermo Fisher Scientific, Basel, Switzerland).

\section{Experiment Design}

Cells were seeded three days before the flight in T25 flasks. One day before the flight, the cells were trypsinized, resuspended and seeded into the $\mu$-slides (ibidi, Gräfelfing, Germany). Subsequently, the tubes were connected and the samples were incubated at $37{ }^{\circ} \mathrm{C}$ over night. On the day of flight, medium was exchanged and the syringes containing $4 \%$ FA were connected. Subsequently, the samples were inserted into the fixation units, which were finally closed and transferred into the rack inside the aircraft.

The first sample was fixed one minute before the first parabola (flight control). The following samples were fixed one minute after the 6th, 11th, 16th, 21st, 26th and the 31st (and last) parabola. In addition, one sample was fixed in the laboratory and therefore did not experience the transfer into the aircraft and the stress of take-off (ground control). After the flight, FA was replaced with PBS and stored at $4{ }^{\circ} \mathrm{C}$ until the samples were stained. The samples were collected in triplicates, originating from three animals (biological replicates).

\section{Immunohistochemical Staining and Imaging}

Samples were permeabilized with $0.5 \%$ Triton X-100 (dissolved in PBS) for five minutes at room temperature and subsequently washed. Unspecific binding was avoided by incubating the samples for 20 minutes at room temperature in blocking buffer containing PBS supplemented with $10 \%$ horse serum (Gibco brand of Thermo Fisher Scientific, Basel, Switzerland). Subsequently, rabbit anti-vimentin antibody (ab92547, Abcam, Cambridge, UK) was incubated for 
one hour at room temperature in blocking buffer. After washing the samples with blocking buffer, the samples were incubated again for one hour in the dark at room temperature with an anti-rabbit antibody conjugated to Texas Red (sc-2780, Santa Cruz Biotechnology, Dallas, USA) and an anti-tubulin antibody conjugated to Alexa Fluor 488 (322,588 Invitrogen brand of Thermo Fisher Scientific, Basel, Switzerland). All antibodies were diluted 1:200 in blocking buffer. Subsequently, the samples were washed again with blocking buffer. Finally, the nuclei were stained with DAPI (diluted 1:6000) in PBS for five minutes at room temperature in the dark and washed again with PBS.

\section{Data Analysis}

From each sample, at least 20 microscopic images were taken at random positions. (Four samples were excluded due to failed fixation. One sample after parabola 6 and 26, and two samples after parabola 11.) The morphology, tubulin and vimentin network of the acquired cells were classified by four independent operators according to Fig. 5. Prior, the images were randomized to blind the operators. The results were normalized to the total number of cells per group (fixation times). In total, 39 to 173 cells were analyzed per group. Difference in distribution was assessed with MATLAB (R2017b) using the Chi-squared test. The Chi-squared test was done separately for all four operators, taking the average from all groups as the expected distribution. $p$-values below the significance level of $5 \%$ were considered as statistically significant.

Furthermore, the distance between the centroids (geometric center) of the cell and the nucleus and the Form Factor of the nucleus were computed (using custom code written in LabVIEW 2016). The two-dimensional cell area (morphology) was determined from the combined fluorescent signals from the tubulin, vimentin and DAPI staining. Likewise, the nuclear area was determined from the DAPI staining only. The Form Factor is a measure for the roundness
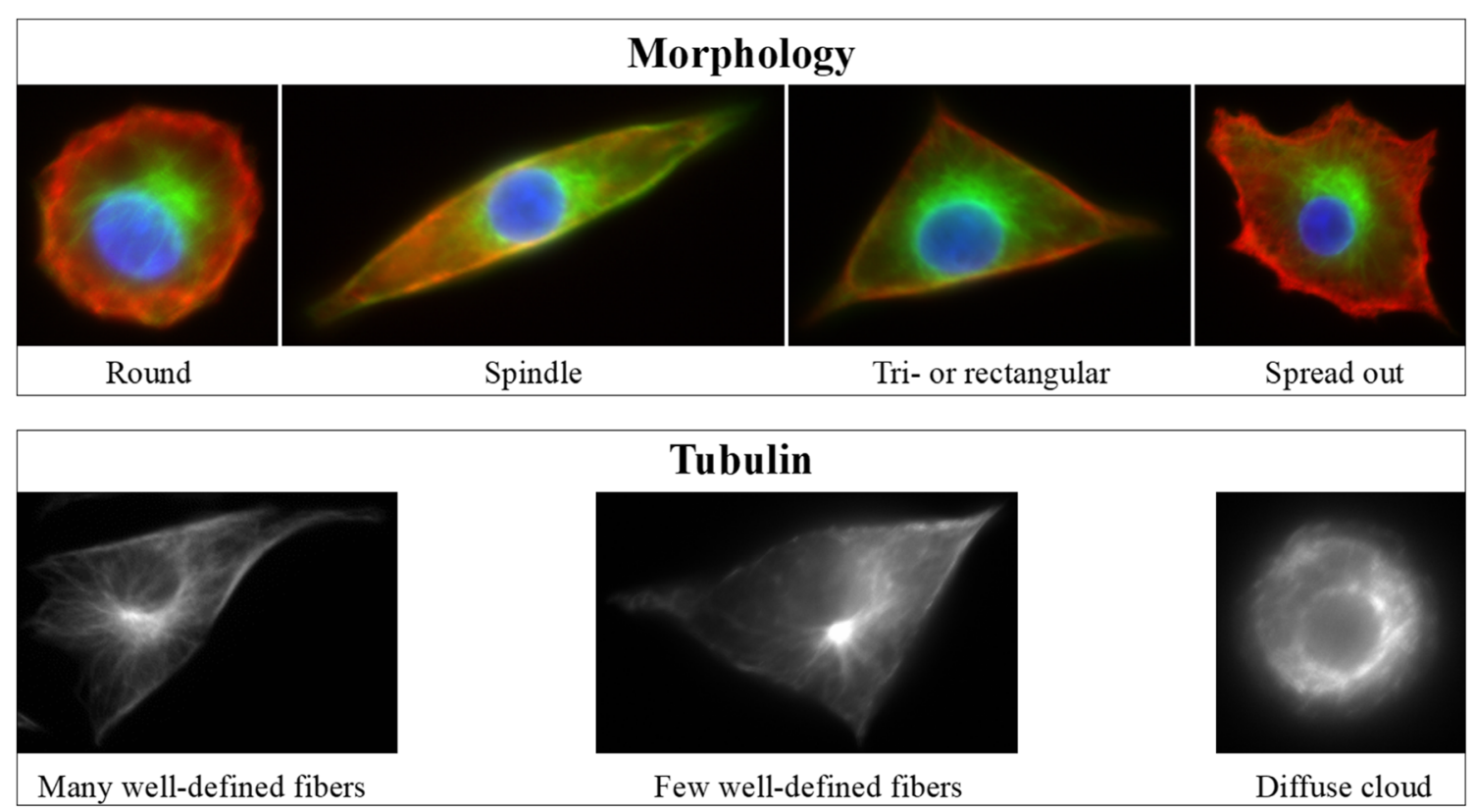

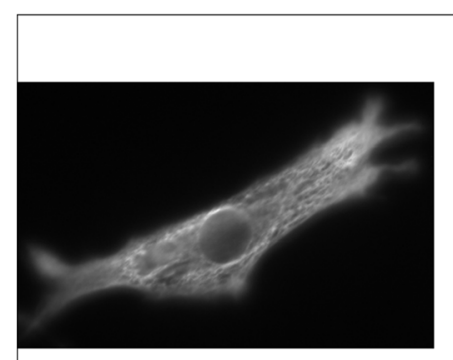

Fibrous

\section{Vimentin}

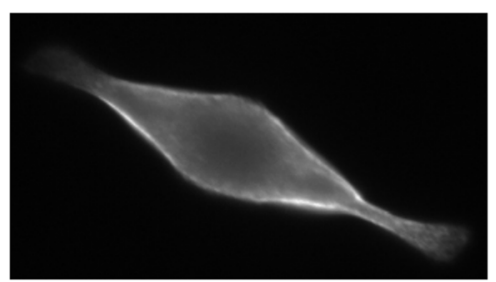

Cortical

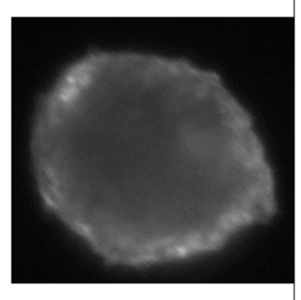

Cloudy
Fig. 5 Microscope images of cells were classified according to their morphology and structure of the tubulin and vimentin network. By the cell morphology (top), the cells were categorized into (1) round, (2) spindle like, (3) tri- or rectangular or (4) spread out. The tubulin network (middle), was categorized into (1) many well-defined fibers, (2) only few well-defined fibers or (3) appear as a diffuse cloud. The vimentin network (bottom), was categorized into (1) cortical (along the cell rim), (2) fibrous structure or (3) cloudy 
of the nucleus and is defined as $4 \pi \mathrm{A} / \mathrm{P}^{2}$, with $\mathrm{A}$ standing for the area and $\mathrm{P}$ for the perimeter of the nucleus. A value equal to one would represent a perfectly circular shape. Statistically significant difference was computed pairwise for all conditions with MATLAB (R2017b) using the non-parametric Wilcoxon rank sum test.

\section{Results}

The microscopic pictures showed a large heterogeneity among the cells in morphology as well as in the structure of the tubulin (Fig. 6) and vimentin (Fig. 7) network. This heterogeneity was detectable within each group (fixation time point),

Fig. 6 Representative images of the tubulin staining. The samples were fixed in the laboratory on ground (ground control), before the first parabola (flight control) and one minute after the 6 th, 11 th, 16th, 21st, 26th and 31st parabola. In all, no obvious changes or adaptions in tubulin structure could be detected during the course of the flight
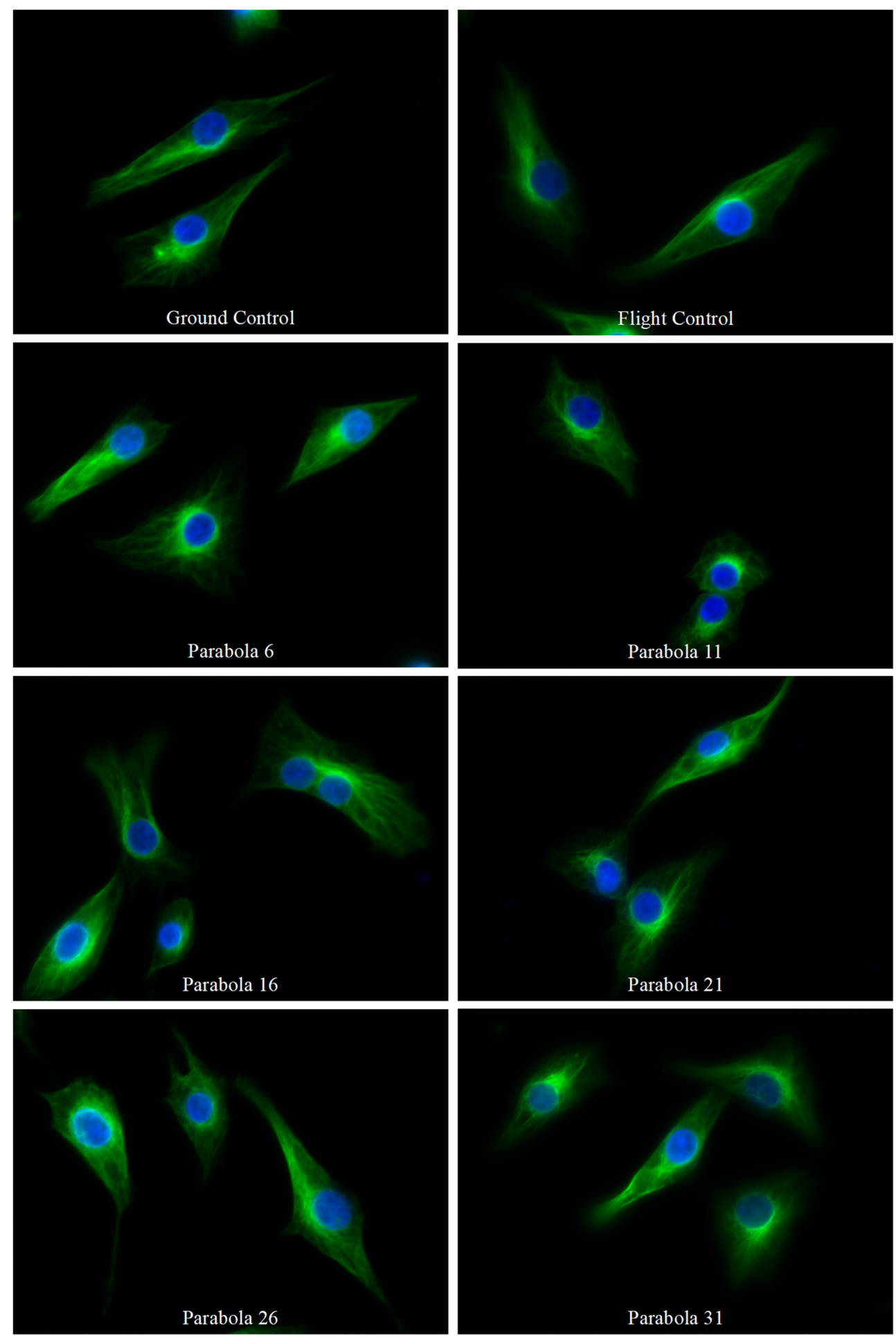
Fig. 7 Representative images of the vimentin staining. The samples were fixed in the laboratory on ground (ground control), before the first parabola (flight control) and one minute after the 6th, 11th, 16th, 21st, 26th and 31 st parabola. In all, no obvious changes or adaptions in vimentin network could be

detected during the course of the flight
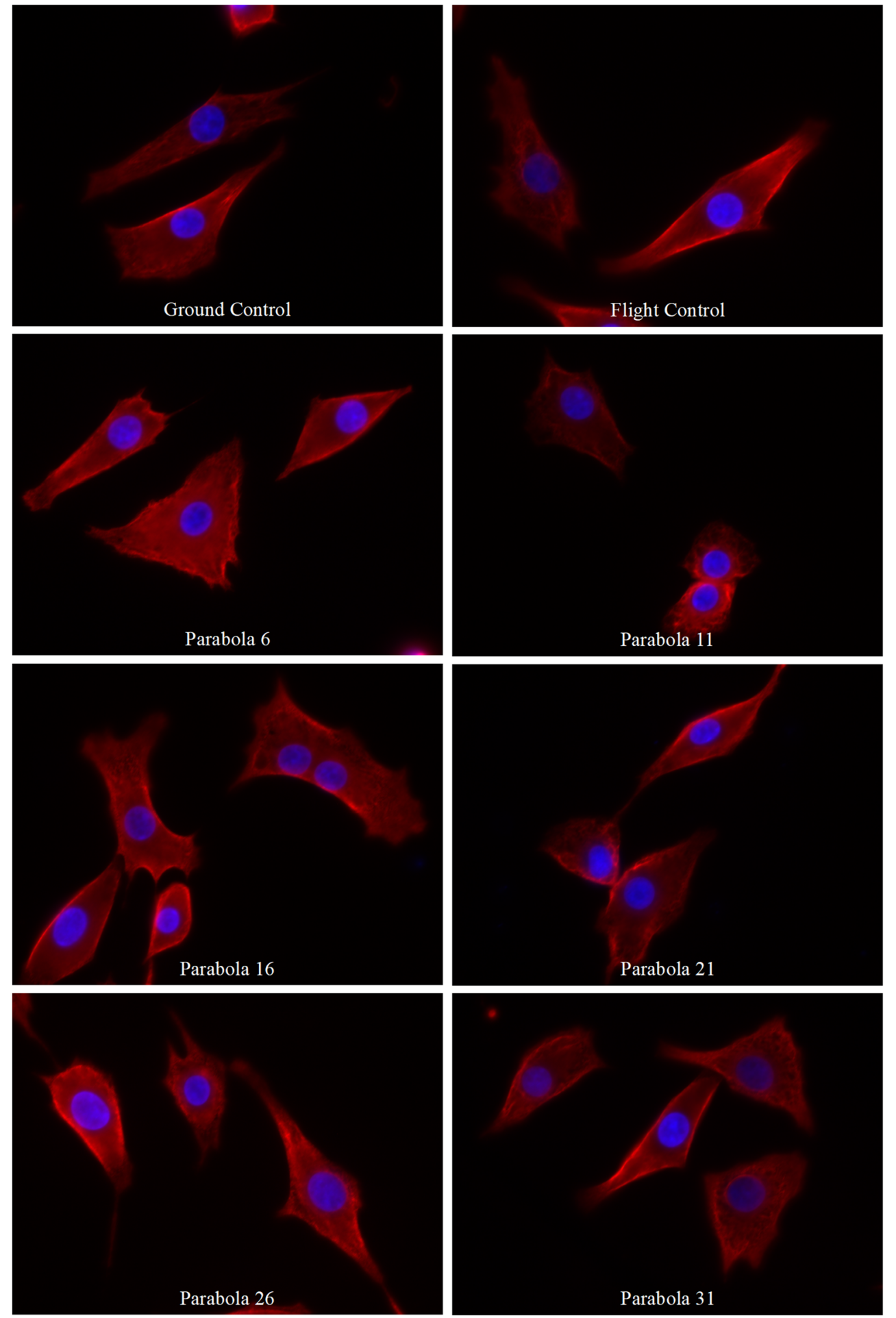

yet little difference in heterogeneity could be detected between groups. To quantify the outcome of the experiment, the cells on the images were classified according to Fig. 5, by their morphology and the structure of their tubulin and vimentin networks (Figs. 8 and 9). The results showed that overall the classification by the four operators was reasonably consistent. Even though the spread of the individual points within the groups indicated differences in judgment, the trends across the groups (along the fixation time points) were similar among the operators. The distribution of the four different cell morphologies was similar in all groups.

For the tubulin network, there was a small shift during the flight. The ratio of cells showing "many well-defined fibers" increased slightly, while the ratio of cells showing "few well- 
Fig. 8 The tubulin network was categorized (see Fig. 5) whether it shows many well-defined fibers (blue), few well-defined fibers (green) or appear as a diffuse cloud (red). The classification was done by four blinded individuals (individual marks). The samples were fixed in the laboratory on ground (Gnd. Ctr.) before the first parabola (Flg. Ctr.) and one minute after the 6 th, 11 th, 16th, 21st, 26th and 31st parabola. Small horizontal lines indicate the median values, which are connected by a hypothetical spline

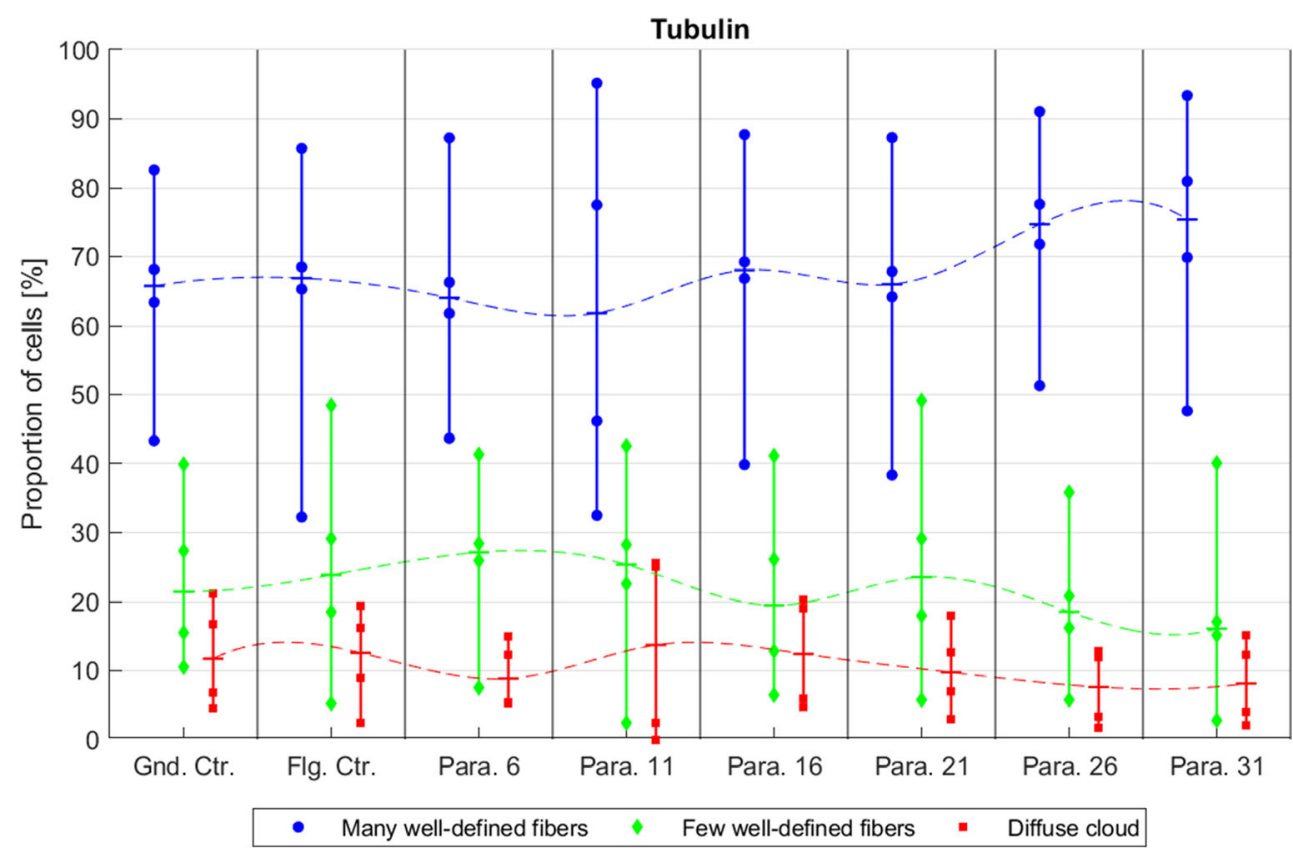

defined fibers" decreased (Fig. 8). The difference between the ground control and the flight control, which experienced the transfer into the aircraft and the stress of take-off, was rather minor (Fig. 8). The data was also analyzed separately for the four cell morphologies. This showed that the shift from "few well-defined fibers" to "many well-defined fibers" was mainly visible in cells having a "spindle" or "spread out" morphology (Fig. 10). The outliers seen in parabola 11 were likely due to the fact that two out of three samples had to be excluded at this timepoint.
Conversely, for the vimentin network, a slight increase appeared in cells showing a "cortical" and a slight decrease appeared in cells showing a "fibrous" network (Fig. 9). However, the difference between the ground and flight control showed that the transfer into the aircraft and take-off already affected the vimentin network (Fig. 9). The separation by the morphology showed that the shift of cells showing a "fibrous" to "cortical" network was mainly seen in cells having a "tri- or rectangular" shape (Fig. 11).
Fig. 9 The vimentin network was categorized (see Fig. 5) whether it appears mainly as a fibrous structure (blue), a cortical structure (green), or cloudy (red). The classification was done by four blinded individuals (individual marks). The samples were fixed in the laboratory on ground (Gnd. Ctr.), before the first parabola (Flg. Ctr.) and one minute after the 6th, 11th, 16th, 21st, 26th and 31st parabola. Small horizontal lines indicate the median values, which are connected by a hypothetical spline

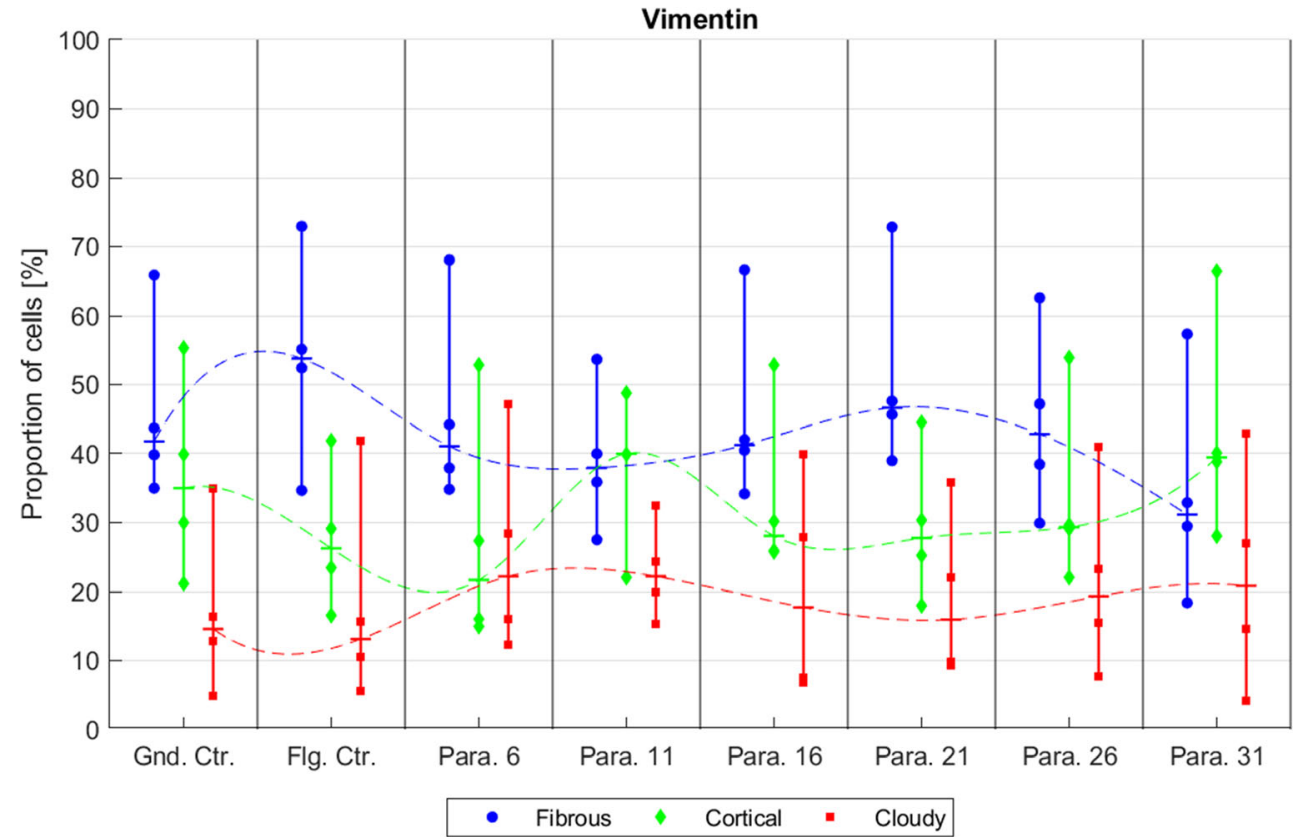



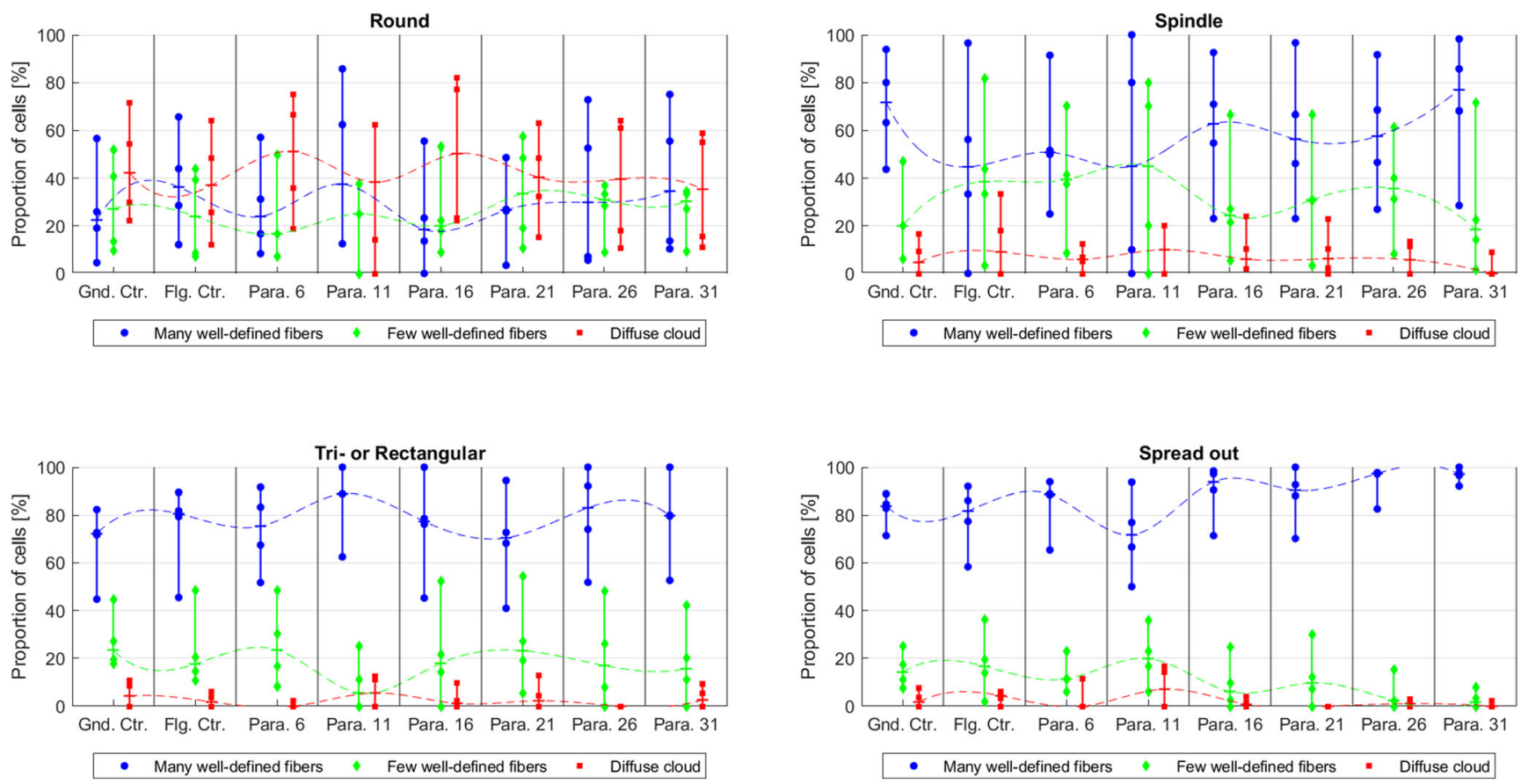

Fig. 10 Categorized tubulin network as in Fig. 8 and separated by the cell morphology

However, statistical analysis using the Chi-squared test showed there was no clear statistically significant difference in distribution. The Chi-squared test was done separately for all four operators to respect the paired nature of the data points. Again, the data points in parabola $11 \mathrm{can}$ be considered as outliers since two samples had to be excluded in this timepoint. Therefore, this data point is backed by considerably fewer cells than in the other time points, and the cells originated only from one instead of three animals. Apart from the parabola 11, none of the operators detected any difference in the tubulin network (Table 1). For the vimentin network, one out of four operators detected a statistically significant difference in the flight control group and after parabola 6 . In the samples
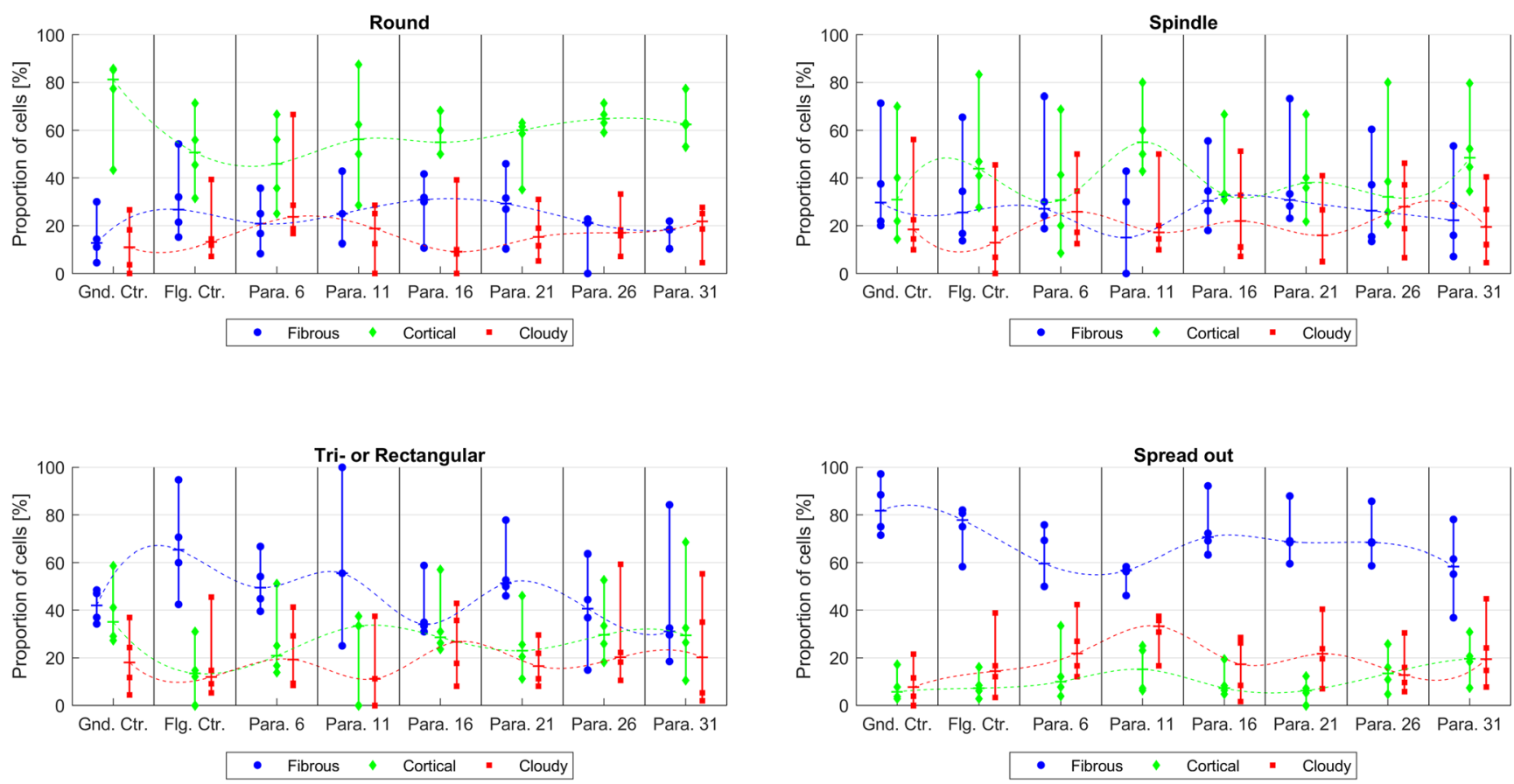

Fig. 11 Categorized vimentin network as in Fig. 9 and separated by the cell morphology 
Table $1 p$-values of the Chi-squared test assessing differences in the distribution of the tubulin network. The test has been done for all four operators separately to respect the paired nature of the data points. The average from all groups was used as the expected distribution. Statistically significant differences (smaller than 5\%) are marked with an asterisk and printed in bold

\begin{tabular}{lllllllll}
\hline Operator & Gnd. Ctr. & Flg. Ctr. & Para. 6 & Para. 11 & Para. 16 & Para. 21 & Para. 26 & Para. 31 \\
\hline $\mathbf{1}$ & 0.543 & 0.626 & 0.249 & 0.165 & 0.529 & 0.635 & 0.415 \\
$\mathbf{2}$ & 0.092 & 0.288 & 0.778 & 0.131 & 0.946 & 0.808 & 0.622 \\
$\mathbf{3}$ & 0.517 & 0.923 & 0.119 & $* \mathbf{0 . 0 0 1}$ & 0.299 & 0.975 & 0.206 \\
$\mathbf{4}$ & 0.884 & 0.197 & 0.843 & $* \mathbf{0 . 0 4 8}$ & 0.810 & 0.329 & 0.114 \\
\hline
\end{tabular}

taken after parabola 31, two out of four operators detected a statistically significant difference (Table 2).

Since several microgravity experiments demonstrated changes in the location and shape of the nucleus (HughesFulford and Lewis 1996; Hughes-Fulford et al. 2006; Nabavi et al. 2011), the distance between the centroids (geometric center) of the cell and the nucleus, as well as the Form Factor (measure for roundness) of the nucleus, were determined. No statistically significant difference was found for the distance between the centroids of the cell and the nucleus among any condition (Fig. S1, Table S1). For the Form Factor of the nucleus, statistically significant difference was only found between the ground control and the samples fixed after parabola 16 and 26, which is likely a coincidence finding (Fig. S2, Table S2).

\section{Discussion and Conclusion}

Tubulin is known to play important roles in cell morphology, mechanical stability of the cell, cytokinesis as well as protein trafficking and secretion. In articular chondrocytes, tubulin is crucial for the synthesis and secretion of extracellular matrix proteins including collagen and proteoglycans (reviewed in (Blain 2009)). The function of vimentin is less known, but it is thought to mechanically stabilize the cells and support the synthesis of extracellular matrix proteins (reviewed in (Blain 2009)). In this study, we examined if the tubulin or vimentin network of bovine articular chondrocytes shows adaptations under altered gravity condition during a parabolic flight.
Therefore, we developed a novel hardware, which performed as expected.

In the acquired microscopic images, a small shift from cells showing a "few well-defined fibers" toward cells showing "many well-defined fibers" was observe for the duration of the flight in the tubulin network (Fig. 8). Similarly, a small shift from cells showing a "cortical" toward cells showing a "fibrous" vimentin network was observed (Fig. 9). Since the ratio of the different morphologies was similar in all groups (time points), we conclude that the data is not biased by the selection of acquired images. Furthermore, the independent operators classifying the cells were blinded and the images were displayed in a random order. Despite differences in judgment, the overall trend of the data remained consistent. Therefore, we conclude that the observed finding was not biased by the personal judgment of operators classifying the cells.

Since chondrocytes dedifferentiate in standard 2D cell culture and acquire a fibroblast-like phenotype (reviewed in (Charlier et al. 2019)), we did not expand the cells after isolation and kept the time in culture as short as possible. The chondrocyte phenotype could be preserved by embedding the cells in 3D matrices (reviewed in (Charlier et al. 2019)). However, we abstained from doing so to guarantee rapid fixation of the cells. We also did not apply any coating, such as collagen or fibronectin, to our culture chambers since the coating has only limited influence on dedifferentiation and cell morphology (Brodkin et al. 2004; Barbero et al. 2006; Kino-Oka et al. 2005). The surface properties of the culture chambers used during the flight, however, might slightly modulate the formation of focal adhesions and by consequence the
Table 2 p-values of the Chi-squared test assessing differences in the distribution of the vimentin network. The test has been done for all four operators separately to respect the paired nature of the data points. The average over all groups was used as the expected distribution. Statistically significant differences (smaller than 5\%) are marked with an asterisk and printed in bold

\begin{tabular}{llrrrrrrr}
\hline Operator & Gnd. Ctr. & Flg. Ctr. & Para. 6 & Para. 11 & Para. 16 & Para. 21 & Para. 26 & Para. 31 \\
\hline $\mathbf{1}$ & 0.215 & 0.069 & 0.273 & 0.368 & 0.444 & 0.755 & 0.720 & 0.078 \\
$\mathbf{2}$ & 0.961 & 0.251 & 0.417 & $* \mathbf{0 . 0 0 7}$ & 0.146 & 0.227 & 0.859 \\
$\mathbf{3}$ & 0.441 & $* \mathbf{0 . 0 3 1}$ & 0.282 & $* \mathbf{0 . 0 3 8}$ & 0.847 & 0.315 & 0.929 & $* \mathbf{0 . 0 1 3}$ \\
$\mathbf{4}$ & 0.646 & 0.536 & $* \mathbf{0 . 0 1 2}$ & $* \mathbf{0 . 0 3 6}$ & 0.838 & 0.332 & 0.897 & $* \mathbf{0 . 0 0 7}$ \\
\hline
\end{tabular}


organization of the cytoskeleton. In addition, the experiment was performed only on a single day. The daily condition (e.g. quality of the parabolas) may influence the experiment outcome as well. However, the characteristics of the flight were comparable to previous parabolic flights in duration, temperature, quality and number of parabolas. From previous experience with the system we can thus infer that the daily conditions most likely had only a neglectable effect on the results.

The effects seen in the tubulin and vimentin network were small and statistically not significant. We were therefore unable to detect an adaptation in the tubulin or vimentin network for the duration of the parabolic flight. This interpretation is in disagreement to a previous study on human articular chondrocytes, where a disruption of the tubulin network and holes in the vimentin network were observed after 31 parabolas (Aleshcheva et al. 2015). The reasons for the discrepancies are unclear and remain speculative. Possible reasons could be the difference in species, cell passages or used hardware. In Aleshcheva et al., commercially available chondrocytes from human donors were expanded prior to the experiment, due to the limited amount of available cells. This unpreventably leads to an adaptation of the cells to the culture condition and to the development of a fibroblast-like phenotype through dedifferentiation (reviewed in (Charlier et al. 2019)). In contrast, we used chondrocytes isolated from healthy cattle, which were only briefly kept in culture. Furthermore, the hardware setup in the two experiments was quite different. The former experiment was performed in partly filled slide flasks, which allowed for the cell culture medium to flow across the cells during the flight. In this study the cells were seeded in channels which were completely filled with culture medium. The small channel dimension ( $0.8 \mathrm{~mm}$ high and $5 \mathrm{~mm}$ wide), inhibit undesired fluid movement, but at the same time ensure rapid and complete fixation. Overall, the discrepancy between the two studies stresses the importance of repeating experiments with different experiment setups and cell sources. If the contradicting outcomes is the result of cell sources or differences in hardware and experiment design shall be addressed in future experiments.

In this study, multiple samples were fixed at different time points, and therefore the analysis could only be done over a population of cells and did not allow to follow up individual cells during the course of the parabolic flight. Therefore, it is possible that small adaptations in the cytoskeleton could not be detected. Indeed, by using in-situ live-cell imaging on a human thyroid carcinoma cell line (FTC-133), small changes in the cytoskeleton network could be observed during a single parabola (Corydon et al. 2016).

With the small but statistically non-significant shifts observed in the tubulin and vimentin network, we conclude that the microtubules and vimentin network is insensitive to altered gravity during a parabolic flight in primary bovine chondrocytes.
Acknowledgements First of all, we thank the European Space Agency (ESA) and Novespace (Bordeaux, France) for organizing and conducting the parabolic flight campaign. We also thank PRODEX (ESA), the Swiss Space Office (SSO) and the Lucerne School of Engineering and Architecture (Switzerland) for their financial support. We further acknowledge Binder (Tuttlingen, Germany) and B. Braun (Sempach, Switzerland) for their support and the Genossenschaft Schlachthaus Ei (Sarnen, Switzerland) for providing the bovine joints. Ultimately, we thank Nicole Wittkopf for the administrative support during the parabolic flight preparation.

Author Contributions SW: Study design, software, mechanical design, conduction of experiment, data analysis, preparation of manuscript and figures, finances

JA: Mechanical design

SG: Electrical design, software

CZ: Electrical design

CJ: Software

CG: Conduction of experiment, cell classification

GC: Conduction of experiment, cell classification

$\mathrm{MC}$ : Conduction of experiment

KR: Cell classification

CF: Cell classification

OS: Electrical design

GS: Mechanical design

ME: Finances

FI: Study design

Funding Information Open access funding provided by Lucerne University of Applied Sciences and Arts. This study has been funded through PRODEX (ESA), the Swiss Space Office (SSO) and the Lucerne School of Engineering and Architecture (Switzerland).

\section{Compliance with Ethical Standards}

Conflict of Interest The authors declare that they have no conflicts of interest.

Data Availability The data is available from the corresponding author upon reasonable request.

Open Access This article is licensed under a Creative Commons Attribution 4.0 International License, which permits use, sharing, adaptation, distribution and reproduction in any medium or format, as long as you give appropriate credit to the original author(s) and the source, provide a link to the Creative Commons licence, and indicate if changes were made. The images or other third party material in this article are included in the article's Creative Commons licence, unless indicated otherwise in a credit line to the material. If material is not included in the article's Creative Commons licence and your intended use is not permitted by statutory regulation or exceeds the permitted use, you will need to obtain permission directly from the copyright holder. To view a copy of this licence, visit http://creativecommons.org/licenses/by/4.0/.

\section{References}

Akkiraju, H., Nohe, A.: Role of chondrocytes in cartilage formation. Progression of Osteoarthritis and Cartilage Regeneration. Journal of developmental biology. 3(4), 177-192 (2015). https://doi.org/ 10.3390/jdb3040177 
Aleshcheva, G., Wehland, M., Sahana, J., Bauer, J., Corydon, T.J., Hemmersbach, R., Frett, T., Egli, M., Infanger, M., Grosse, J., Grimm, D.: Moderate alterations of the cytoskeleton in human chondrocytes after short-term microgravity produced by parabolic flight maneuvers could be prevented by up-regulation of BMP-2 and SOX-9. FASEB journal : official publication of the Federation of American Societies for Experimental Biology. 29(6), 2303-2314 (2015). https://doi.org/10.1096/fj.14-268151

Anderson, D.E., Johnstone, B.: Dynamic mechanical compression of chondrocytes for tissue engineering: a critical review. Frontiers in bioengineering and biotechnology. 5, 76 (2017). https://doi.org/10. 3389/fbioe.2017.00076

Barbero, A., Grogan, S.P., Mainil-Varlet, P., Martin, I.: Expansion on specific substrates regulates the phenotype and differentiation capacity of human articular chondrocytes. J. Cell. Biochem. 98(5), 11401149 (2006). https://doi.org/10.1002/jcb.20754

Barlič, A., Drobnič, M., Maličev, E., Kregar-Velikonja, N.: Quantitative analysis of gene expression in human articular chondrocytes assigned for autologous implantation. J. Orthop. Res. 26(6), 847853 (2008). https://doi.org/10.1002/jor.20559

Bennell, K.L., Hinman, R.S.: A review of the clinical evidence for exercise in osteoarthritis of the hip and knee. J. Sci. Med. Sport. 14(1), 49 (2011). https://doi.org/10.1016/j.jsams.2010.08.002

Blain, E.J.: Involvement of the cytoskeletal elements in articular cartilage homeostasis and pathology. Int. J. Exp. Pathol. 90(1), 1-15 (2009). https://doi.org/10.1111/j.1365-2613.2008.00625.x

Brodkin, K.R., Garcia, A.J., Levenston, M.E.: Chondrocyte phenotypes on different extracellular matrix monolayers. Biomaterials. 25(28), 5929-5938 (2004). https://doi.org/10.1016/j.biomaterials.2004.01. 044

Buckwalter, J.A., Mow, V.C., Ratcliffe, A.: Restoration of injured or degenerated articular cartilage. J Am Acad Orthop Surg. 2(4), 192-201 (1994)

Charlier, E., Deroyer, C., Ciregia, F., Malaise, O., Neuville, S., Plener, Z., Malaise, M., de Seny, D.: Chondrocyte dedifferentiation and osteoarthritis (OA). Biochem. Pharmacol. 165, 49-65 (2019). https://doi. org/10.1016/j.bcp.2019.02.036

Corydon, T.J., Kopp, S., Wehland, M., Braun, M., Schutte, A., Mayer, T., Hulsing, T., Oltmann, H., Schmitz, B., Hemmersbach, R., Grimm, D.: Alterations of the cytoskeleton in human cells in space proved by life-cell imaging. Sci. Rep. 6, 20043 (2016). https://doi.org/10.1038/ srep20043

Diaz-Romero, J., Gaillard, J.P., Grogan, S.P., Nesic, D., Trub, T., MainilVarlet, P.: Immunophenotypic analysis of human articular chondrocytes: changes in surface markers associated with cell expansion in monolayer culture. J. Cell. Physiol. 202(3), 731-742 (2005). https://doi.org/10.1002/jcp.20164

Diaz-Romero, J., Nesic, D., Grogan, S.P., Heini, P., Mainil-Varlet, P.: Immunophenotypic changes of human articular chondrocytes during monolayer culture reflect bona fide dedifferentiation rather than amplification of progenitor cells. J. Cell. Physiol. 214(1), 75-83 (2008). https://doi.org/10.1002/jcp.21161

Eyckmans, J., Boudou, T., Yu, X.: Chen, Christopher S.: a Hitchhiker's guide to Mechanobiology. Dev. Cell. 21(1), 35-47 (2011). https:// doi.org/10.1016/j.devcel.2011.06.015

Fitzgerald, J.: Cartilage breakdown in microgravity-a problem for longterm spaceflight? NPJ Regenerative medicine. 2, 10 (2017). https:// doi.org/10.1038/s41536-017-0016-1

Fletcher, D.A., Mullins, R.D.: Cell mechanics and the cytoskeleton. Nature. 463(7280), 485-492 (2010). https://doi.org/10.1038/ nature 08908

Grad, S., Eglin, D., Alini, M., Stoddart, M.J.: Physical stimulation of chondrogenic cells in vitro: a review. Clin. Orthop. Relat. Res. 469(10), 2764-2772 (2011). https://doi.org/10.1007/s11999-011$1819-9$
Grosse, J., Wehland, M., Pietsch, J., Ma, X., Ulbrich, C., Schulz, H., Saar, K., Hubner, N., Hauslage, J., Hemmersbach, R., Braun, M., van Loon, J., Vagt, N., Infanger, M., Eilles, C., Egli, M., Richter, P., Baltz, T., Einspanier, R., Sharbati, S., Grimm, D.: Short-term weightlessness produced by parabolic flight maneuvers altered gene expression patterns in human endothelial cells. FASEB journal : official publication of the Federation of American Societies for Experimental Biology. 26(2), 639-655 (2012). https://doi.org/10. 1096/fj.11-194886

Haqqi, T.M., Anthony, D.D., Malemud, C.J.: Chondrocytes. In: Tsokos, G.C. (ed.) Principles of Molecular Rheumatology, pp. 267-277. Humana Press, Totowa (2000)

Hughes-Fulford, M., Lewis, M.L.: Effects of microgravity on osteoblast growth activation. Exp. Cell Res. 224(1), 103-109 (1996). https:// doi.org/10.1006/excr.1996.0116

Hughes-Fulford, M., Rodenacker, K., Jutting, U.: Reduction of anabolic signals and alteration of osteoblast nuclear morphology in microgravity. J. Cell. Biochem. 99(2), 435-449 (2006). https://doi.org/10. 1002/jcb.20883

Ingber, D.E.: Tensegrity I. Cell structure and hierarchical systems biology. Journal of cell science. 116(Pt 7), 1157-1173 (2003a)

Ingber, D.E.: Tensegrity II. How structural networks influence cellular information processing networks. Journal of cell science. 116(Pt 8), 1397-1408 (2003b)

Janmey, P.A., McCulloch, C.A.: Cell mechanics: integrating cell responses to mechanical stimuli. Annu. Rev. Biomed. Eng. 9, 1-34 (2007). https://doi.org/10.1146/annurev.bioeng.9.060906.151927

Johnston, S.L., Campbell, M.R., Scheuring, R., Feiveson, A.H.: Risk of herniated nucleus pulposus among U.S. astronauts. Aviation, space, and environmental medicine. 81(6), 566-574 (2010). https://doi.org/ 10.3357/asem.2427.2010

Kang, S.W., Yoo, S.P., Kim, B.S.: Effect of chondrocyte passage number on histological aspects of tissue-engineered cartilage. Biomed Mater Eng. 17(5), 269-276 (2007)

Karmali, F., Shelhamer, M.: The dynamics of parabolic flight: flight characteristics and passenger percepts. Acta astronautica. 63(5-6), 594-602 (2008). https://doi.org/10.1016/j.actaastro.2008.04.009

Kino-Oka, M., Yashiki, S., Ota, Y., Mushiaki, Y., Sugawara, K., Yamamoto, T., Takezawa, T., Taya, M.: Subculture of chondrocytes on a collagen type I-coated substrate with suppressed cellular dedifferentiation. Tissue Eng. 11(3-4), 597-608 (2005). https://doi.org/ $10.1089 /$ ten.2005.11.597

Lin, Z., Fitzgerald, J.B., Xu, J., Willers, C., Wood, D., Grodzinsky, A.J., Zheng, M.H.: Gene expression profiles of human chondrocytes during passaged monolayer cultivation. Journal of orthopaedic research : official publication of the Orthopaedic Research Society. 26(9), 1230-1237 (2008). https://doi.org/10.1002/jor.20523

Loon, J.J.W.A.V.: Micro-Gravity and Mechanomics. Gravitational and Space Biology. 20(2), (2007)

Marlovits, S., Hombauer, M., Truppe, M., Vecsei, V., Schlegel, W.: Changes in the ratio of type-I and type-II collagen expression during monolayer culture of human chondrocytes. J Bone Joint Surg Br. 86(2), 286-295 (2004)

Mobasheri, A., Carter, S.D., Martin-Vasallo, P., Shakibaei, M.: Integrins and stretch activated ion channels; putative components of functional cell surface mechanoreceptors in articular chondrocytes. Cell Biol. Int. 26(1), 1-18 (2002). https://doi.org/10.1006/cbir.2001. 0826

Nabavi, N., Khandani, A., Camirand, A., Harrison, R.E.: Effects of microgravity on osteoclast bone resorption and osteoblast cytoskeletal organization and adhesion. Bone. 49(5), 965-974 (2011). https:// doi.org/10.1016/j.bone.2011.07.036

Ohashi, K., Fujiwara, S., Mizuno, K.: Roles of the cytoskeleton, cell adhesion and rho signalling in mechanosensing and mechanotransduction. J. Biochem. 161(3), 245-254 (2017). https://doi.org/10.1093/jb/mvw082 
Pletser, V., Kumei, Y.: Parabolic Flights. In: Beysens, D.A., van Loon, J.J.W.A. (eds.) Generation and Applications of Extra-Terrestrial Environments on Earth. River Publishers Series in Standardisation, pp. 61-73. River Publishers (2015)

Pletser, V., Rouquette, S., Friedrich, U., Clervoy, J.-F., Gharib, T., Gai, F., Mora, C.: The first European parabolic flight campaign with the Airbus A310 ZERO-G. Microgravity science and technology. 28(6), 587-601 (2016). https://doi.org/10.1007/s12217-016-9515-8

Rajagopal, V., Holmes, W.R., Lee, P.V.S.: Computational modeling of single-cell mechanics and cytoskeletal mechanobiology. Wiley interdisciplinary reviews. Systems biology and medicine. 10(2), (2018). https://doi.org/10.1002/wsbm.1407

Ramachandran, V., Wang, R., Ramachandran, S.S., Ahmed, A.S., Phan, K., Antonsen, E.L.: Effects of spaceflight on cartilage: implications on spinal physiology. Journal of spine surgery. 4(2), 433-445 (2018). https://doi.org/10.21037/jss.2018.04.07

Roos, E.M., Arden, N.K.: Strategies for the prevention of knee osteoarthritis. Nat. Rev. Rheumatol. 12(2), 92-101 (2016). https://doi.org/ 10.1038/nrrheum.2015.135

Rosner, H., Wassermann, T., Moller, W., Hanke, W.: Effects of altered gravity on the actin and microtubule cytoskeleton of human $\mathrm{SH}-$ SY5Y neuroblastoma cells. Protoplasma. 229(2-4), 225-234 (2006). https://doi.org/10.1007/s00709-006-0202-2

Schulze-Tanzil, G.: Activation and dedifferentiation of chondrocytes: implications in cartilage injury and repair. Ann. Anat. 191(4), 325-338 (2009). https://doi.org/10.1016/j.aanat.2009.05.003

Tekari, A., Luginbuehl, R., Hofstetter, W., Egli, R.J.: Chondrocytes expressing intracellular collagen type II enter the cell cycle and coexpress collagen type I in monolayer culture. Journal of orthopaedic research : official publication of the Orthopaedic Research Society. 32(11), 1503-1511 (2014). https://doi.org/10.1002/jor.22690

Ulbrich, C., Pietsch, J., Grosse, J., Wehland, M., Schulz, H., Saar, K., Hubner, N., Hauslage, J., Hemmersbach, R., Braun, M., van Loon, J., Vagt, N., Egli, M., Richter, P., Einspanier, R., Sharbati, S., Baltz, T., Infanger, M., Ma, X., Grimm, D.: Differential gene regulation under altered gravity conditions in follicular thyroid cancer cells: relationship between the extracellular matrix and the cytoskeleton.
Cellular physiology and biochemistry : international journal of experimental cellular physiology, biochemistry, and pharmacology. 28(2), 185-198 (2011). https://doi.org/10.1159/000331730

Ulrich-Vinther, M., Maloney, M.D., Schwarz, E.M., Rosier, R., O'Keefe, R.J.: Articular cartilage biology. JAAOS - Journal of the American Academy of Orthopaedic Surgeons. 11(6), 421-430 (2003)

Vorselen, D., Roos, W.H., MacKintosh, F.C., Wuite, G.J., van Loon, J.J.: The role of the cytoskeleton in sensing changes in gravity by nonspecialized cells. FASEB journal : official publication of the Federation of American Societies for Experimental Biology. 28(2), 536-547 (2014). https://doi.org/10.1096/fj.13-236356

Wang, N.: Review of Cellular Mechanotransduction. Journal of physics D: Applied physics. 50(23), (2017). https://doi.org/10.1088/13616463/aa6e18

Wang, J.H., Thampatty, B.P.: An introductory review of cell mechanobiology. Biomech. Model. Mechanobiol. 5(1), 1-16 (2006). https://doi.org/10.1007/s10237-005-0012-z

Wang, N., Tytell, J.D., Ingber, D.E.: Mechanotransduction at a distance: mechanically coupling the extracellular matrix with the nucleus. Nat. Rev. Mol. Cell Biol. 10(1), 75-82 (2009). https://doi.org/10. $1038 / \mathrm{nrm} 2594$

Wang, J., Lü, D., Mao, D., Long, M.: Mechanomics: an emerging field between biology and biomechanics. Protein Cell. 1-14 (2014). https://doi.org/10.1007/s13238-014-0057-9

Wuest, S.L., Calio, M., Wernas, T., Tanner, S., Giger-Lange, C., Wyss, F., Ille, F., Gantenbein, B., Egli, M.: Influence of Mechanical Unloading on Articular Chondrocyte Dedifferentiation. International journal of molecular sciences. 19(5), (2018). https:// doi.org/10.3390/ijms19051289

Yang, F., Dai, Z., Tan, Y., Li, Y.: Effects of altered gravity on the cytoskeleton of neonatal rat Cardiocytes. Microgravity science and technology. 22(1), 45-52 (2010). https://doi.org/10.1007/s12217-0089103-7

Publisher's Note Springer Nature remains neutral with regard to jurisdictional claims in published maps and institutional affiliations. 